\title{
Liquid Titanium Solute Diffusion Measured by Pulsed Ion-Beam Melting
}

\section{Citation}

Sanders, P. G., Michael O. Thompson, Tim J. Renk, and Michael J. Aziz. 2000. Liquid titanium solute diffusion measured by pulsed ion-beam melting. Metallurgical and Materials Transactions A 32(12): 2969-2974.

\section{Published Version}

http://dx.doi.org/10.1007/s11661-001-0171-1

\section{Permanent link}

http://nrs.harvard.edu/urn-3:HUL.InstRepos:2797298

\section{Terms of Use}

This article was downloaded from Harvard University's DASH repository, and is made available under the terms and conditions applicable to Other Posted Material, as set forth at http:// nrs.harvard.edu/urn-3:HUL.InstRepos:dash.current.terms-of-use\#LAA

\section{Share Your Story}

The Harvard community has made this article openly available.

Please share how this access benefits you. Submit a story.

Accessibility 
1 October, 1999

\title{
Liquid Titanium Solute Diffusion Measured by Pulsed Ion-Beam Melting
}

\author{
P. G. Sanders, M. O. Thompson ${ }^{1}$, T. J. Renk ${ }^{2}$, and M. J. Aziz \\ Division of Engineering and Applied Sciences, Harvard University, Cambridge, MA 02138 \\ ${ }^{1}$ Materials Science and Engineering Department, Cornell University, Ithaca, NY 14853 \\ ${ }^{2}$ Sandia National Laboratories, Albuquerque, NM 87185
}

\begin{abstract}
The diffusivities of $\mathrm{Sn}, \mathrm{Mo}, \mathrm{Zr}$, and $\mathrm{Hf}$ in liquid Ti were determined by pulsed ion-beam melting of thin liquid layers. Time-resolved optical reflectance and one-dimensional heat-flow simulations were employed to determine the melt duration. The broadening of nearly Gaussian solute concentration-depth profiles was determined ex situ using Rutherford backscattering spectrometry. Solute diffusivities in the range of 5 to $9 \times 10^{-5} \mathrm{~cm}^{2} / \mathrm{s}$ were determined at temperatures in the range of 2200 to $2500 \mathrm{~K}$. Calculations of buoyancy and Marangoni convection indicate that convective contamination is unlikely.
\end{abstract}

\section{Introduction}

$\mathrm{Ti}$ alloys are important commercial materials in the aerospace industry because of their high strength to weight ratio. The manufacture of Ti components often involves melting to obtain the desired alloy composition and casting. In understanding the process of alloy solidification and solute partitioning, the liquid diffusivity is a critical parameter. In addition to the absence of experimental measurements of $\mathrm{Ti}$ solute liquid diffusivities in the literature ${ }^{1,2}$, there is also a general deficit in knowledge of the thermophysical properties of the liquid phase, including latent heat, specific heat, and thermal conductivity. This paper reports on direct experimental determination of liquid diffusivities of some common alloying elements in Ti.

Liquid diffusivity is a particularly challenging property to measure accurately. Two potentially serious problems associated with liquid diffusivity measurements are convective contamination and container wall interactions ${ }^{1}$. The elevated melting point $\left(\mathrm{T}_{\mathrm{m}}\right)$ and high reactivity of Ti exacerbate both of 
these problems. Convective contamination generally occurs when temperature gradients in the liquid create instabilities leading to the formation of convective cells. High temperatures and extended times increase the likelihood of cell formation. Although it is exceedingly difficult to completely eliminate convective contamination in terrestrial diffusion measurements, these effects can be minimized by using fine capillaries that limit the formation of convection cells. Although container wall interactions have been ruled out in some diffusion experiments with low $\mathrm{T}_{\mathrm{m}}$ materials ${ }^{3}$, there is a general concern that fine capillaries introduce additional problems due to wall interactions-a particularly troublesome concern when working with reactive materials at high temperatures. Although microgravity diffusion measurements can effectively eliminate buoyancy convective currents, surface tension-driven flows (Marangoni) may remain.

Liquid diffusivity measurements following pulsed melting can minimize many of these difficulties. The thin film geometry and short melt duration permit the avoidance of convection currents. The planar geometry permits accurate measurement of the sub-micron diffusion distances resulting from the short melt duration using techniques such as Rutherford backscattering spectrometry (RBS) or secondary ion mass spectrometry. While molten, the liquid is surrounded by a solid of the same composition, so container wall interactions are minimized. The primary difficulties inherent in this method are the accurate measurement of the melt duration, the temporal melt-depth profile, and the liquid temperature. These parameters are generally deduced from time-resolved reflectivity measurements (TRR) and heat-flow simulations.

The vast majority of transient diffusion experiments have utilized pulsed lasers to create the melt. Recently, diffusion measurements following pulsed ion induced melts have been demonstrated for arsenic in silicon ${ }^{4}$. There are several advantages of pulsed ion-beam melting over pulsed laser melting. Unlike a laser beam, the ion beam is completely absorbed, making it unnecessary to determine the energy lost by reflection in order to model the heat flow. In addition, because the ion beam energy is absorbed over depth scales of $\sim 1 \mu \mathrm{m}$ instead of $\sim 0.01 \mu \mathrm{m}$, temperature gradients at the surface are lower than for a laser beam at similar absorbed energy. This leads to more uniform energy absorption and less surface damage. 


\section{Experimental}

Samples were fabricated from $1 \mathrm{~mm}$ thick $99.9 \%$ pure Ti sheet (Alfa Aesar). The sheet was sheared into rectangles $25 \mathrm{~mm}$ long by $8 \mathrm{~mm}$ wide and the specimens were polished to a mirror finish $(0.05$ $\mu \mathrm{m}$ alumina) using conventional metallographic techniques. The samples were ion implanted at energies ranging from 100 to $230 \mathrm{keV}$ with common alloying elements in Ti including the alpha stabilizer Sn, the beta stabilizer Mo, and two elements, $\mathrm{Zr}$ and $\mathrm{Hf}$, in the same family as $\mathrm{Ti}$ (Table I). The samples were melted by an intense nitrogen beam with a pulse length of $200 \mathrm{~ns}$ and total fluences of 1.5 to $3.5 \mathrm{~J} / \mathrm{cm}^{2}$ (Fig. 1). The useful fluence range chosen was bounded on the low end by the melting threshold and on the high end by significant ablation. Because the Ti optical reflectivity changes only slightly upon melting and and could not be used directly to determine the melt durations, small ( 4 by 2 by $0.3 \mathrm{~mm}$ ) silicon rectangles were placed on top of the Ti within the region to be melted. Optical reflectivity changes resulting from melting and solidifying of $\mathrm{Si}$ were used to determine the ion energy fluence using well-established heat-flow simulations $^{5}$ for $\mathrm{Si}$. The fluence determined in this way was used in the Ti heat flow simulations to calculate the melt-depth profile ${ }^{4}$. Composition profiles before and after melting were determined by RBS using 4.5 $\mathrm{MeV}^{4} \mathrm{He}^{2+}$ ions at normal incidence with a detector resolution of $21 \mathrm{keV}$. In addition to direct measurements of the Si melt duration, the incident ions were collected by two Faraday cups mounted on either side of the sample (Fig. 1). The total ion current consisted of $\mathrm{H}^{+}, \mathrm{N}^{+}$, and $\mathrm{N}^{2+}$ ions. The absolute ion flux (ions $/ \mathrm{cm}^{2} / \mathrm{s}$ ) and accelerating potential were determined for each irradiation.

After irradiation, cross-sectional transmission electron microscopy (TEM) samples were prepared with a Hitachi FB-2000A focused ion beam (FIB). Samples were electrodischarge machined into $150 \mu \mathrm{m}$ sections and then mechanically polished to $50 \mu \mathrm{m}$. A thick (150 nm) Au coating was deposited prior to the standard W coating to maintain the original surface for melt depth determination. The near surface region of the samples was thinned to $<1 \mu \mathrm{m}$ by a $30 \mathrm{keV} \mathrm{Ga}$ ion beam with beam currents of $15 \mathrm{nA}$ to $10 \mathrm{pA}$. TEM images were obtained on a Hitachi 8100 microscope operating at $200 \mathrm{keV}$.

\section{Data Analysis}

The ion beam current signal collected by the Faraday cup was split into its three constituent parts as shown in Fig. 2. The relative fractions of the ion species were determined by time-of-flight extraction 
from the ion current ${ }^{4}$. For these simulations, the depth and time dependent energy deposition of each ion species was handled independently. Silicon heat-flow simulations ${ }^{4}$ were performed to determine the total ion beam energy by scaling the ion beam current to match the Si melt duration determined by reflectivity (Fig. 3 and Table II). Because the thermophysical properties of Si are well known, the accuracy of this part of the analysis is good. The ion beam current profile and calculated fluence were then used as input for Ti heat flow simulations ${ }^{4}$ to determine the $\mathrm{Ti}$ melt profile (Fig. 4 and Table II). Uncertainties in this calculation are larger, since the thermophysical properties of $\mathrm{Ti}$ (Table III) are not as well known, especially for the liquid and phase transitions. The heat-flow simulation program did not attempt to model any solid state phase transitions. To account for the heat of transformation without modeling directly the solid state transition, the solid specific heat between the transition temperature and $\mathrm{T}_{\mathrm{m}}$ was increased to recover the correct solid enthalpy at $\mathrm{T}_{\mathrm{m}}$. The $\mathrm{Ti}$ melt duration was typically less than half that of $\mathrm{Si}$, primarily because of Ti's higher melting point and solid heat capacity.

Initial impurity profiles following ion implantation were extracted from RBS data. Simulations using the Edgeworth function ${ }^{11}$ for the implanted concentration profile and the detector resolution were fit to the data. The Edgeworth fitting parameters were then used to model the implanted solute profile (Fig. 5), effectively deconvoluting the RBS instrument function from the raw RBS solute profiles.

The Ti melt profile and initial solute concentration profile were then used as inputs to a onedimensional diffusion equation ${ }^{12}$ to obtain the final solute concentration profile (Fig. 5). RBS profiles, calculated from the diffusion simulation results, were compared to the experimental RBS profile from the melted specimen (Fig. 6). Diffusivities from 3 to $11 \times 10^{-5} \mathrm{~cm}^{2} / \mathrm{s}$ were input into the diffusion simulation and chi-squared minimization (weighted by counting statistics) was used to identify the best-fit diffusivity.

\section{Results}

The results of the liquid Ti solute diffusion calculations are shown in Table II. The maximum solute penetration depth was only one quarter of the maximum melt depth in the Ti (Fig. 4), indicating that convective mixing was not a large factor. The good agreement between the best-fit diffusivities for each solute is demonstrated by the low standard errors ${ }^{13}$ (Table IV). Both the Mo and Hf data sets seem to have one outlier when compared with the tightness of the $\mathrm{Sn}$ and $\mathrm{Zr}$ data sets, but application of Chauvenet's 
criterion ${ }^{13}$ indicates that these data points cannot be excluded. The total error ${ }^{13}$ (Table IV) was calculated by including an additional 5\% systematic uncertainty from determination of the melt duration, the ion-beam energy, and the simulated melt profile.

\section{Discussion}

Upon slow heating, Ti undergoes a solid-state phase transformation from alpha to beta at $1155 \mathrm{~K}$. All simulations reported in this work assumed melting and solidification of the high temperature beta phase. Very rapid melting and solidification could preclude the formation of the high-temperature beta phase, in which case the alpha would melt and solidify at its metastable melting point ${ }^{14}$ of $1696 \mathrm{~K}$. Heatflow simulations were used to determine the maximum interface velocity and heating rate during melting $\left(125 \mathrm{~m} / \mathrm{s}\right.$ and $\left.10^{11} \mathrm{~K} / \mathrm{s}\right)$ and the maximum velocity and cooling rate during solidification $\left(5 \mathrm{~m} / \mathrm{s}\right.$ and $10^{9}$ $\mathrm{K} / \mathrm{s}$ ). Melt duration is a critical parameter in the diffusion simulations, because any error in the calculated melt duration yields a proportional error in the diffusivity. Although rapid melting may allow the alpha to melt at $1696 \mathrm{~K}$, this would only increase the melt duration by $10 \mathrm{~ns}(<1 \%)-$ a negligible change. The solidification rate is relatively slow, suggesting that solidification of the high temperature beta phase will likely occur. Bypassing the beta phase and solidifying instead in the alpha phase would increase the melt duration by $40 \%$. However, this is unlikely to occur at velocities of $5 \mathrm{~m} / \mathrm{s}$ or less. High speed in situ transmission electron microscopy observations of pulsed laser melted $\mathrm{Ti}$ (with heating and cooling rates similar to pulsed ion melting) noted the formation of the high-temperature beta phase during solidification ${ }^{15}$. In addition, RBS studies of pulsed laser melted single crystal Ti found a lack of ion channeling and epitaxy after solidification, possibly due to slip or twin systems associated with the alphabeta phase transition ${ }^{16}$.

An additional verification of the melt profiles determined by heat-flow simulations was done by comparing the calculated melt depth to the experimentally measured depths. Cross-sectional TEM indicates a melt depth of $1400 \mathrm{~nm}$ for sample Mo2 (Fig. 7). The simulated melt depth for this sample is $1300 \mathrm{~nm}$, which is in good agreement with the measured value. If the low-temperature alpha phase had instead melted and solidified at the metastable transformation temperature, the simulated melt depth would be 1500 
nm. Unfortunately, the uncertainty in the experimental depth measurement is larger than the difference between the two simulations due to the surface roughness (Figs. 7 and 8).

The surface roughness in Fig. 8 seems to encompass three length scales. The largest $(\sim 10 \mu \mathrm{m})$ features probably result from inhomogeneities in the ion beam. The remnants of the polishing media and other particulates can lead to hot spots on the specimen surface and the creation of the medium-size $(\sim 3$ $\mu \mathrm{m})$ craters. The smallest $(\sim 0.3 \mu \mathrm{m})$ features appear to be distinctive crystallographic features from the martensitic transformation of beta to alpha. These features are very similar those observed ${ }^{16}$ on $<0001>\mathrm{Ti}$, in which linear features had trigonal symmetry and crystallographic faceting. It is likely that these linear features result from the transformation of beta to alpha during cooling, supporting the solidification parameters used in this paper (Table III) for determining the melt-depth profile. The surface roughness should not affect the RBS concentration-depth profiles, because the RBS data is averaged over a large area $\left(3 \mathrm{~mm}^{2}\right)$ and relative motion of the surface in the $\mathrm{z}$ direction does not change the solute concentration with respect to the surface.

The low solute solubility of Mo in $\alpha$-Ti (Table I) could lead to second phase formation upon transformation from $\beta$-Ti to $\alpha$-Ti. However, the relatively rapid solidification rate may likely lead to solute trapping of the Mo and the formation of a super-saturated single-phase solution. The formation of Mo-rich regions should not occur until the low temperature $\alpha$-Ti forms around $1155 \mathrm{~K}$ (Table I), well below the melting point of $1941 \mathrm{~K}$ where liquid diffusion ceases. No Mo precipitates were observed in cross-sectional TEM (Fig. 7).

A correlation has been observed between diffusivity and the standard free energy of solution. ${ }^{1}$ These observations indicate that the more exothermic the mixing reaction the smaller the liquid diffusivity. The heats of reaction calculated by Miedema ${ }^{17}$ are more exothermic for Sn-Ti $(-62 \mathrm{~kJ} / \mathrm{mol})$ and Mo-Ti (-6 $\mathrm{kJ} / \mathrm{mol}$ ) than those for $\mathrm{Zr}-\mathrm{Ti}$ and Hf-Ti (both $0 \mathrm{~J} / \mathrm{mol}$ ). Thus, at the outset of the experiment, it was expected that the $\mathrm{Zr}$ and Hf would have higher diffusivities due to their chemical similarity and presumed limited interaction with Ti. However, the observed diffusivities of Sn and Mo were higher than $\mathrm{Zr}$ and $\mathrm{Hf}$.

Other thermodynamic parameters can also be used to assess the solution behavior. Strong solute/solvent interactions may lead to the formation of solvent clusters around solute atoms and reduced diffusion rates ${ }^{18}$. Clustering is generally indicated by negative solute partial molar volumes. Turnbull ${ }^{19}$ 
tabulated the molar volumes of different solutes in $\mathrm{Al}$, but volumetric data were not available for liquid $\mathrm{Ti}$ alloys. Observation of the initial liquidus slope in the binary phase diagram can give an independent indication of the exothermicity of the solute/solvent interaction. Generally speaking, for regular solution phase diagrams, the more negative the initial liquidus slope (minus the slope of a straight line connecting the melting points of the pure elements), the more attractive the interaction between the solute and solvent in the liquid. Considering the phase diagrams of Ti-Mo, Ti-Zr, and Ti-Hf, the liquidus slope is significantly more negative for Ti-Zr and Ti-Hf than for Ti-Mo. This trend is consistent with the observed diffusivities (Table IV). The complexity of the Ti-Sn phase diagram lead to its exclusion from the above comparison.

One important parameter in reporting the diffusivity is the temperature. Heat-flow simulations were done to determine the average liquid surface temperature during the course of the experiment (Table II). It is important to point out that the temperature determination is the least accurate parameter obtained from the heat flow simulations. Calculations indicate that the average surface temperature ranges from $\mathrm{T}_{\mathrm{m}}+$ $300 \mathrm{~K}$ to $\mathrm{T}_{\mathrm{m}}+550 \mathrm{~K}$. The temperature dependence of the liquid diffusivity can be described as weakly activated or even linear ${ }^{1}$, leading to the general conclusion that the measured diffusivity corresponds to the average melt temperature. For the measurements in Table II, higher temperatures do not necessarily correspond to larger liquid diffusivities. The ion type used for melting can control temperature variations in the melt. Work is now underway to reduce the overheating above $\mathrm{T}_{\mathrm{m}}$ by using only the lightest ions $\left(\mathrm{H}^{+}\right)$.

Convective contamination is always an issue in liquid diffusion measurements. Buoyancy-driven convection occurs as a result of temperature gradients within the specimen. Instabilities leading to natural convection $^{20}$ can occur if the Rayleigh number $\mathrm{R}>1700$. For the geometry of this experiment, $\mathrm{R}=2 \times 10^{-8}$. Because $\mathrm{R}$ has a cubic dependence on thickness, the likelihood of buoyancy-driven convection becomes significant only at melt depths $>4 \mathrm{~mm}$, which is much greater than the 1 to 3 micron melt depths observed in this work.

Marangoni-driven convection results from surface temperature gradients and the temperature dependence of the surface tension. Calculations of surface tension driven convection using the Stokes solution to a suddenly accelerated flat plate in an infinite liquid ${ }^{21}$ and the surface temperature variations identified in the heat-flow simulations indicate that in the direction normal to the surface, diffusive transport is $5 \times 10^{4}$ faster than Marangoni convection. This results primarily from the aspect ratio of the 
specimen, as the velocity of Marangoni-induced currents in $\mathrm{z}$ is reduced from the surface radial velocity by the depth-to-width ratio of the melt.

There is some synergy between buoyancy- and Marangoni-driven convection, because both tend to create convective currents with the same orientation. However, due to the small contributions from these processes, the overall effect of convection on the measurements is negligible. Note that in Fig. 4 , the maximum solute depth before and after melting is compared with the total melt depth. If convection were present, one would observe solute within the deepest regions of the melt ${ }^{22}$, but none was detected. This supports the claim that convective contamination is not a significant issue in this type of experiment.

\section{Summary}

The Ti liquid solute diffusivity was determined by pulsed ion-beam melting of Ti ion implanted with Sn, Mo, Zr, and Hf. One-dimensional diffusion simulations were utilized to match the final experimental concentration profile given the initial concentration profile and the Ti melt profile. Ti liquid solute diffusivities in $\mathrm{cm}^{2} / \mathrm{s}$ over the temperature range of 2200 to $2500 \mathrm{~K}$ are as follows: $\mathrm{D}_{\mathrm{Sn}}=9.1 \pm 0.5$, $\mathrm{D}_{\mathrm{Mo}}=7.7 \pm 0.6, \mathrm{D}_{\mathrm{Zr}}=5.2 \pm 0.3, \mathrm{D}_{\mathrm{Hf}}=6.2 \pm 0.6$. The solidification of the Ti was slow enough to allow the formation of the high temperature beta phase, which later transformed to the low temperature alpha phase. Calculations of buoyancy and Marangoni convection currents indicate that convective contamination was unlikely.

\section{Acknowledgements}

This research was sponsored by NASA grant NAG8-1256 at Harvard University, CGS at Cornell University, and U.S. DOE contract DE-AC04-94AL85000 at Sandia National Laboratories. Ion implantation was performed in the Surface Modification and Characterization Research Center at Oak Ridge National Laboratory.

\section{References}

${ }^{1}$ T. Iida and R. I. L. Guthrie, The Physical Properties of Liquid Metals (Clarendon, Oxford, England, 1993).

${ }^{2}$ M. Shimoji and T. Itami, Atomic Transport in Liquid Metals (Trans Tech Pub., Zürich, Switzerland, 1986). 
${ }^{3}$ L. B. Jalbert, F. Rosenberger, and R. M. Banish, J. Phys. Condens. Matter 10, 7113 (1998).

${ }^{4}$ M. O. Thompson and T. J. Renk, Mater. Res. Soc. Proc. 504, 33 (1999).

${ }^{5}$ M. J. Aziz, C. W. White, J. Narayan, and B. Stritzker, in Energy Beam-Solid Interactions and Transient Thermal Processing IV, edited by V. T. Nguyen and A. G. Cullis (editions de Physique, Les Ulis Cedex, France, 1985), p. 231.

${ }^{6}$ R. Hultgren, P. D. Desai, D. T. Hawkins, M. Gleiser, K. K. Kelley, and D. D. Wagman, Selected Values of the Thermodynamic Properties of the Elements (American Society for Metals, Metals Park, Ohio, 1973) p. 518.

${ }^{7}$ Y. S. Touloukian and E. H. Buyco, Specific Heat: Metallic Elements and Alloys (Plenum, New York, 1970) p. 257-262.

${ }^{8}$ C. Y. Ho, R. W. Powell, and P. E. Liley, J. Phys. Chem. Ref. Data 3, Suppl. 1, 683 (1974).

${ }^{9}$ V. E. Zinov'ev, V. F. Polev, S. A. Il'inykh, G. P. Zinov'eva, and S. G. Tuluts, Phys. Met. Metall. 6041 (1985).

${ }^{10}$ C. A. MacDonald, A. M. Malvezzi, and F. Spaepen, J. Appl. Phys. 65, 129 (1989).

${ }^{11}$ J. F. Gibbons, Projected Range Statistics: Semiconductors and Related Materials (Halsted, New York, 1975), p. 24.

${ }^{12}$ Solution of one-dimensional diffusion equation with moving interface by Crank-Nicholson algorithm, M. O. Thompson (1998).

${ }^{13}$ P. R. Bevington and D. K. Robinson, Data Reduction and Error Analysis for the Physical Sciences (McGraw-Hill, New York, 1992). p. 58.

${ }^{14}$ J. L. Murray, Metall. Trans. A 19, 243 (1988).

${ }^{15}$ O. Bostanjoglo and D. Otte, Mater. Sci. Eng. A 173, 407 (1993).

${ }^{16}$ L. Buene, E. N. Kaufmann, C. M. Preece, and C. W. Draper, Mater. Res. Soc. Proc. 1, 591 (1981).

${ }^{17}$ A. R. Miedema, Phillips Tech. Rev. 36, 217 (1976).

${ }^{18}$ N. Isono, P. M. Smith, D. Turnbull, and M. J. Aziz, Metall. Mater. Trans. 27A, 725 (1996).

${ }^{19}$ D. Turnbull, Acta Metall. Mater. 38, 243 (1990).

${ }^{20}$ P. H. Roberts, “On Non-Linear Bérnard Convection,” in Non-Equilibrium Thermodynamics: Variational Techniques and Stability (University of Chicago, Chicago, 1966) p. 126. 
${ }^{21}$ J. P. Longtin, K. Hijikata, and K. Ogawa, Int. J. Heat Mass Trans. 42, 85 (1999).

${ }^{22}$ P. Mazzoldi, L. F. Dona dalle Rose, and D. K. Sood, Rad. Eff. 63, 105 (1982). 
Tables

Table I. Ion Implantation Parameters

\begin{tabular}{|l|l|l|l|l|l|l|l|}
\hline Ion & $\begin{array}{l}\text { Energy } \\
(\mathrm{keV})\end{array}$ & $\begin{array}{l}\text { Dose } \\
\left(10^{15} / \mathrm{cm}^{2}\right)\end{array}$ & $\begin{array}{l}\text { Peak Conc. } \\
(\mathrm{at} \%)\end{array}$ & $\begin{array}{l}\text { Peak Depth } \\
(\mathrm{nm})\end{array}$ & $\begin{array}{l}\text { Max. Depth } \\
(\mathrm{nm})\end{array}$ & $\begin{array}{l}\text { Solubility } \\
\text { in } \alpha-\mathrm{Ti}\end{array}$ & $\begin{array}{l}\text { Solubility } \\
\text { in } \beta-\mathrm{Ti}\end{array}$ \\
$($ at. $\%)$
\end{tabular}


Table II. Titanium Diffusion Calculations

\begin{tabular}{|c|c|c|c|c|c|c|c|}
\hline Sample & $\begin{array}{l}\text { Si Melt } \\
\text { Duration } \\
(\mu \mathrm{s})\end{array}$ & $\begin{array}{l}\text { Fluence } \\
\left(\mathrm{J} / \mathrm{cm}^{2}\right)\end{array}$ & $\begin{array}{l}\text { Ti Melt } \\
\text { Duration } \\
\text { (ns) }\end{array}$ & $\begin{array}{l}\text { Ti Melt } \\
\text { Depth } \\
(\mathrm{nm})\end{array}$ & $\begin{array}{l}\text { Max Solute } \\
\text { Diffusion } \\
\text { Depth } \\
\text { (nm) }\end{array}$ & $\begin{array}{l}\text { Diffusivity } \\
\left(10^{-5} \mathrm{~cm}^{2} / \mathrm{s}\right)\end{array}$ & $\begin{array}{l}\text { Average } \\
\text { Surface } \\
\text { Temperature } \\
\text { above } \mathrm{T}_{\mathrm{m}}(\mathrm{K})\end{array}$ \\
\hline $\operatorname{Sn} 1$ & 1.2 & 1.6 & 0.46 & 1200 & 240 & 9.3 & 330 \\
\hline $\operatorname{Sn} 2$ & 2.7 & 2.3 & 1.03 & 1800 & 300 & 8.7 & 480 \\
\hline $\mathrm{Sn} 3$ & 3.8 & 2.8 & 1.40 & 2100 & 350 & 9.2 & 470 \\
\hline Mo1 & 6.3 & 3.5 & 2.39 & 2800 & 380 & 6.6 & 530 \\
\hline Mo2 & 1.5 & 1.8 & 0.58 & 1300 & 240 & 8.2 & 380 \\
\hline Mo3 & 1.1 & 1.6 & 0.42 & 1100 & 220 & 8.2 & 290 \\
\hline $\mathrm{Zr1}$ & 5.8 & 3.4 & 2.21 & 2700 & 340 & 5.4 & 560 \\
\hline $\mathrm{Zr} 2$ & 4.6 & 3.0 & 1.73 & 2400 & 300 & 4.9 & 500 \\
\hline Hf1 & 1.4 & 1.8 & 0.53 & 1200 & 230 & 7.1 & 310 \\
\hline Hf2 & 5.0 & 3.1 & 1.87 & 2500 & 340 & 6.0 & 500 \\
\hline Hf3 & 2.1 & 2.1 & 0.79 & 1500 & 240 & 5.5 & 400 \\
\hline
\end{tabular}


Table III. Titanium Thermophysical Properties

\begin{tabular}{|c|c|c|}
\hline Property & Value & Comments \\
\hline melting temperature & $1941 \mathrm{~K}$ & \\
\hline heat of fusion & $15 \mathrm{~kJ} / \mathrm{mol}$ & Average of $14.6 \mathrm{~kJ} / \mathrm{mol}^{\mathrm{a}}$ and $15.4 \mathrm{~kJ} / \mathrm{mol}^{\mathrm{b}}$ \\
\hline heat of transformation & $4.2 \mathrm{~kJ} / \mathrm{mol}^{\mathrm{b}}$ & Added to solid specific heat function (see Data Analysis) \\
\hline solid specific heat & $\begin{array}{l}-2.61+1.97 * \log \\
\mathrm{T}\end{array}$ & Logarithmic fit to Touloukina curves 6 and $14^{\mathrm{c}}$ \\
\hline solid thermal conductivity & $\begin{array}{l}0.29-3.74 \times 10^{-4} \mathrm{~T} \\
+4.57 \times 10^{-7} \mathrm{~T}^{2}- \\
2.06 \times 10^{-10} \mathrm{~T}^{3}+ \\
3.50 \times 10^{-14} \mathrm{~T}^{4}\end{array}$ & Polynomial fit to recommended values ${ }^{\mathrm{d}}$ \\
\hline liquid specific heat & $38 \mathrm{~J} /(\mathrm{mol} \mathrm{K})^{\mathrm{b}}$ & Estimate \\
\hline liquid thermal conductivity & $30 \mathrm{~W} /(\mathrm{m} \mathrm{K})$ & Added anomalous increase ${ }^{\mathrm{e}}$ to $\mathrm{T}_{\mathrm{m}}$ solid value $^{\mathrm{d}}$ \\
\hline freezing/melting response & $0.5\left(\mathrm{~T}_{\mathrm{m}}-\mathrm{T}\right) \mathrm{m} / \mathrm{s}$ & Used Eq. $11^{\mathrm{f}}$ with entropy of fusion of $8 \mathrm{~J} / \mathrm{mol} \mathrm{K}^{\mathrm{b}}$ \\
\hline
\end{tabular}
a. Reference 1
b. Reference 6
c. Reference 7
d. Reference 8
e. Reference 9
f. Reference 10 
Table IV. Average Diffusivity and Uncertainty

\begin{tabular}{|l|l|l|l|}
\hline Solute & $\begin{array}{l}\text { Diffusivity } \\
\left(10^{-5} \mathrm{~cm}^{2} / \mathrm{s}\right)\end{array}$ & $\begin{array}{l}\text { Standard Error } \\
\left(10^{-5} \mathrm{~cm}^{2} / \mathrm{s}\right)\end{array}$ & $\begin{array}{l}\text { Total Error } \\
\left(10^{-5} \mathrm{~cm}^{2} / \mathrm{s}\right)\end{array}$ \\
\hline $\mathrm{Sn}$ & 9.1 & 0.2 & 0.5 \\
\hline Mo & 7.7 & 0.5 & 0.6 \\
\hline $\mathrm{Zr}$ & 5.2 & 0.2 & 0.3 \\
\hline Hf & 6.2 & 0.5 & 0.6 \\
\hline
\end{tabular}




\section{Figure captions}

Fig 1. Schematic of sample geometry, in which FC denotes Faraday Cup. The silicon used for reflectivity measurements covers a portion of the titanium area exposed to the ion beam.

Fig. 2. Ion beam current from pulse used to melt sample $\mathrm{Sn} 2$.

Fig. 3. Determination of the Si melt duration from the Si reflectivity trace for sample Sn2.

Fig. 4. Simulated melt-depth profile for sample Sn2. For comparison, the maximum solute depths before and after melting are also shown.

Fig. 5. The solute concentration-depth profile before and after ion melting of sample Sn2. The initial profile was obtained by fitting of the RBS spectra (including deconvolution of the detector function). The final profile was simulated from the initial profile and the best-fit diffusivity.

Fig. 6. Comparison of Rutherford backscattering spectrometry data from sample Sn2 with diffusion simulation results for three diffusivity values. The top scale is the depth associated with the Sn scattering.

Fig. 7. Cross-sectional transmission electron microscopy image of sample Mo2 that had a $1.4 \mu \mathrm{m}$ melt depth.

Fig. 8. Scanning electron microscopy images of the surface of sample Hf2, showing the three scales of surface roughness: large variations $(\sim 10 \mu \mathrm{m})$ due to beam inhomogeneities (a), medium-sized craters $(\sim 5$ $\mu \mathrm{m})$ resulting from surface impurities (a), and small features $(\sim 1 \mu \mathrm{m})$ due to the solid-state phase transition (b). 
Side View

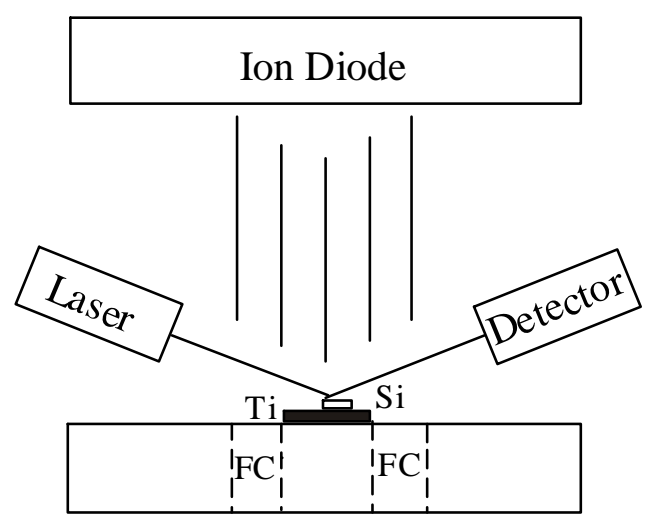

Top View

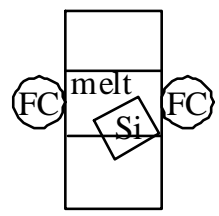

$\mathrm{Ti}$

Fig 1. Schematic of sample geometry, in which FC denotes Faraday Cup. The silicon used for reflectivity measurements covers a portion of the titanium area exposed to the ion beam. 


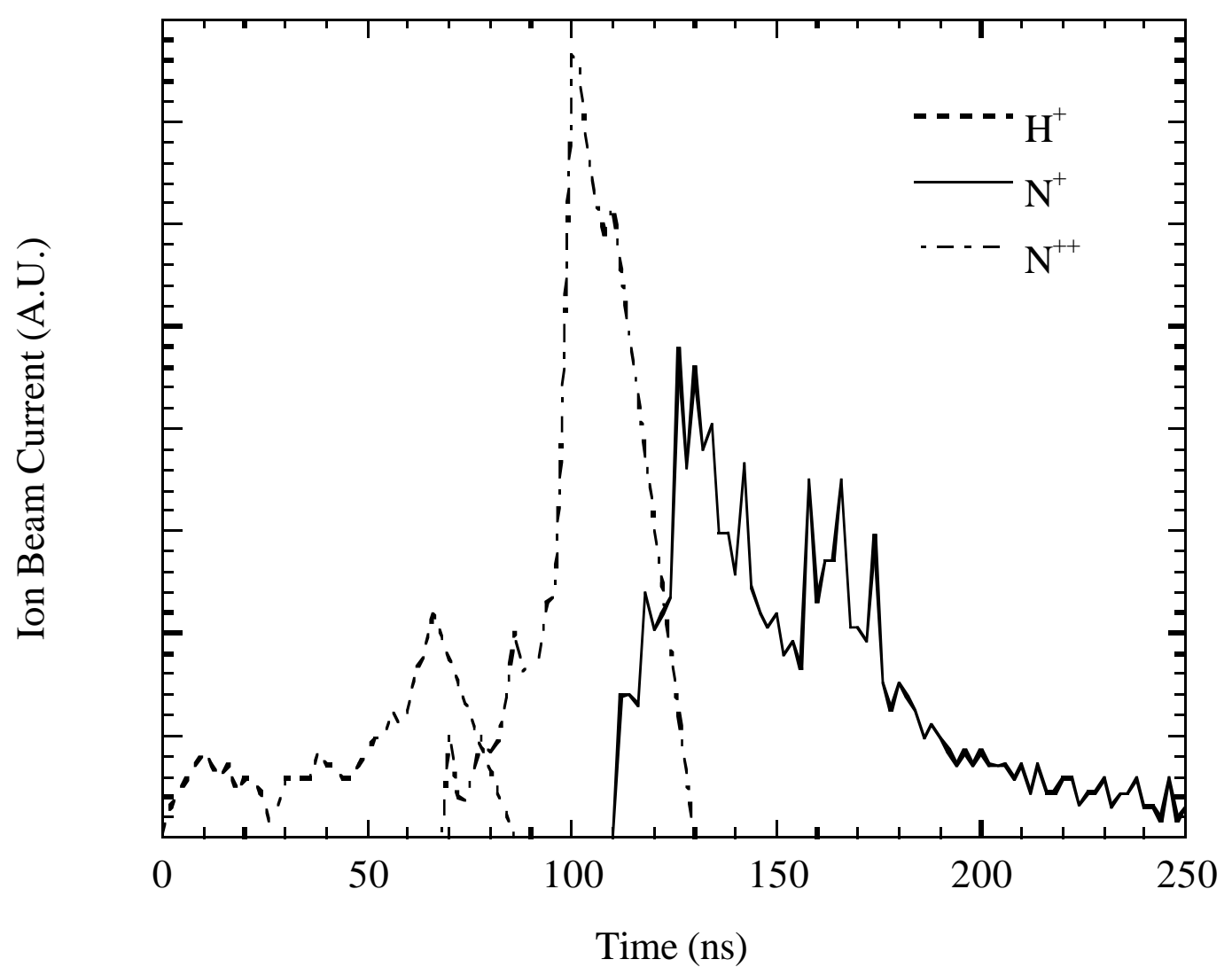

Fig. 2. Ion beam current from pulse used to melt sample Sn2. 


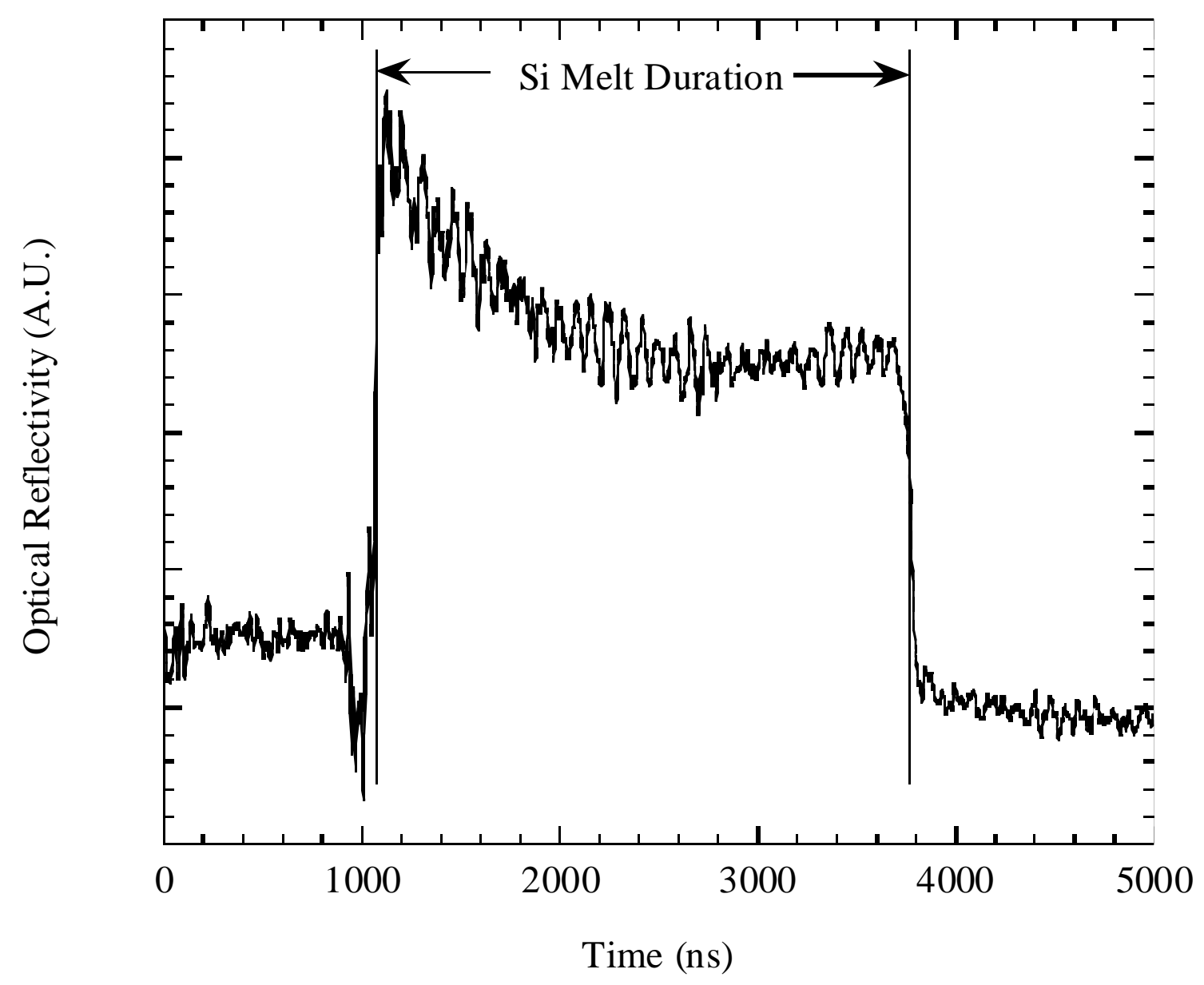

Fig. 3. Determination of the Si melt duration from the Si reflectivity trace for sample Sn2. 


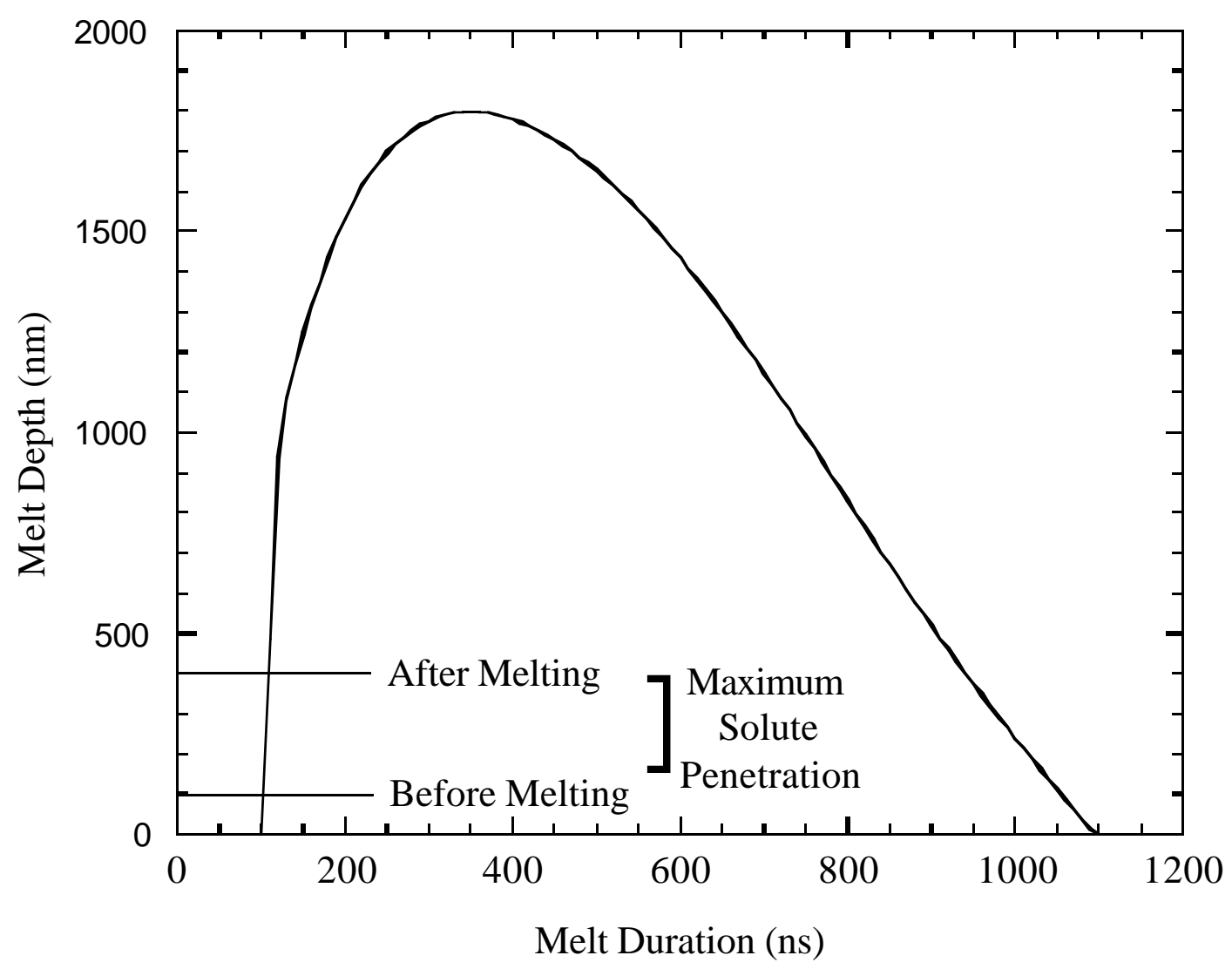

Fig. 4. Simulated melt-depth profile for sample Sn2. For comparison, the maximum solute depths before and after melting are also shown. 


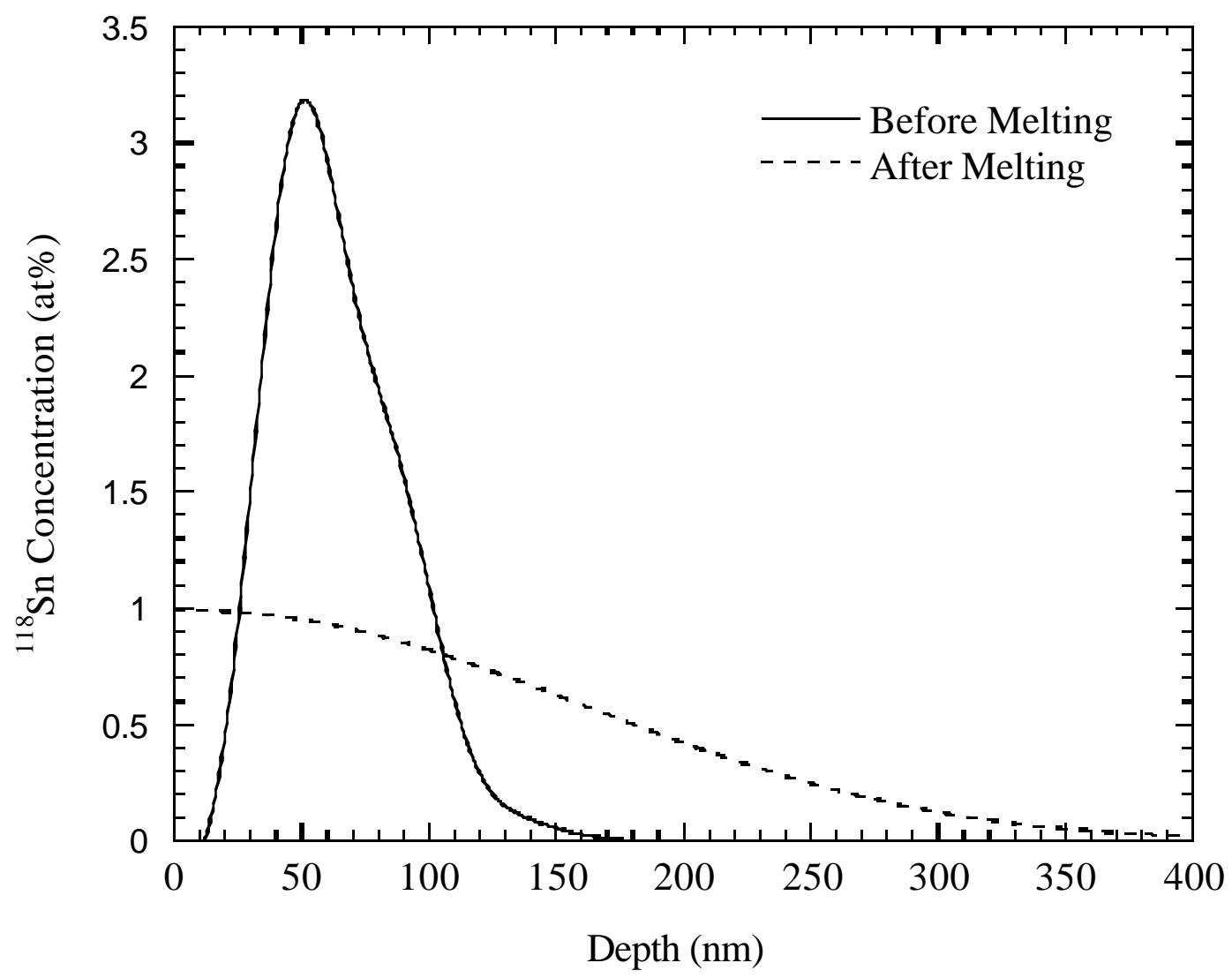

Fig. 5. The solute concentration-depth profile before and after ion melting of sample Sn2. The initial profile was obtained by fitting of the RBS spectra (including deconvolution of the detector function). The final profile was simulated from the initial profile and the best-fit diffusivity. 


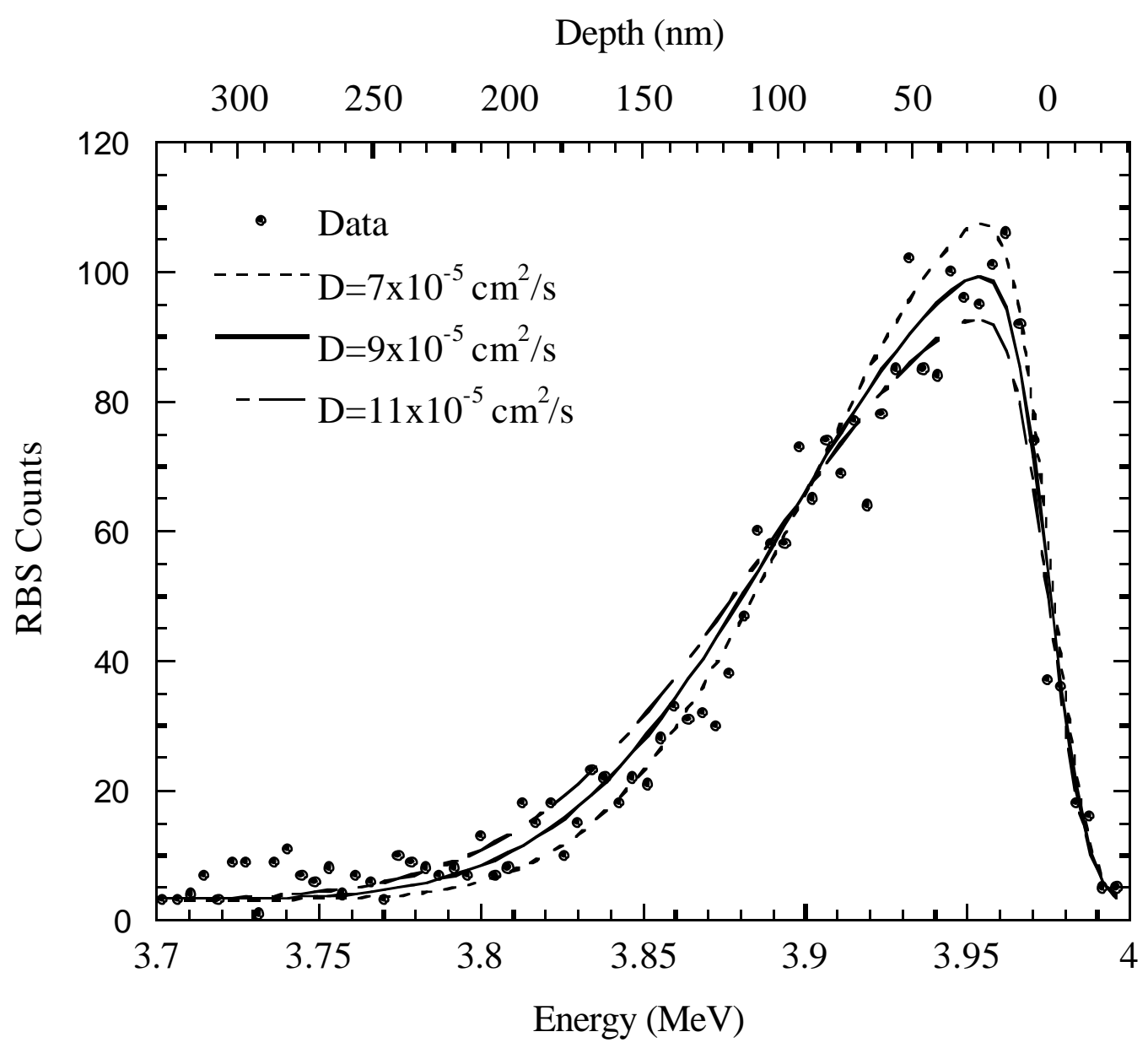

Fig. 6. Comparison of Rutherford backscattering spectrometry data from sample Sn2 with diffusion simulation results for three diffusivity values. The top scale is the depth associated with the Sn scattering. 


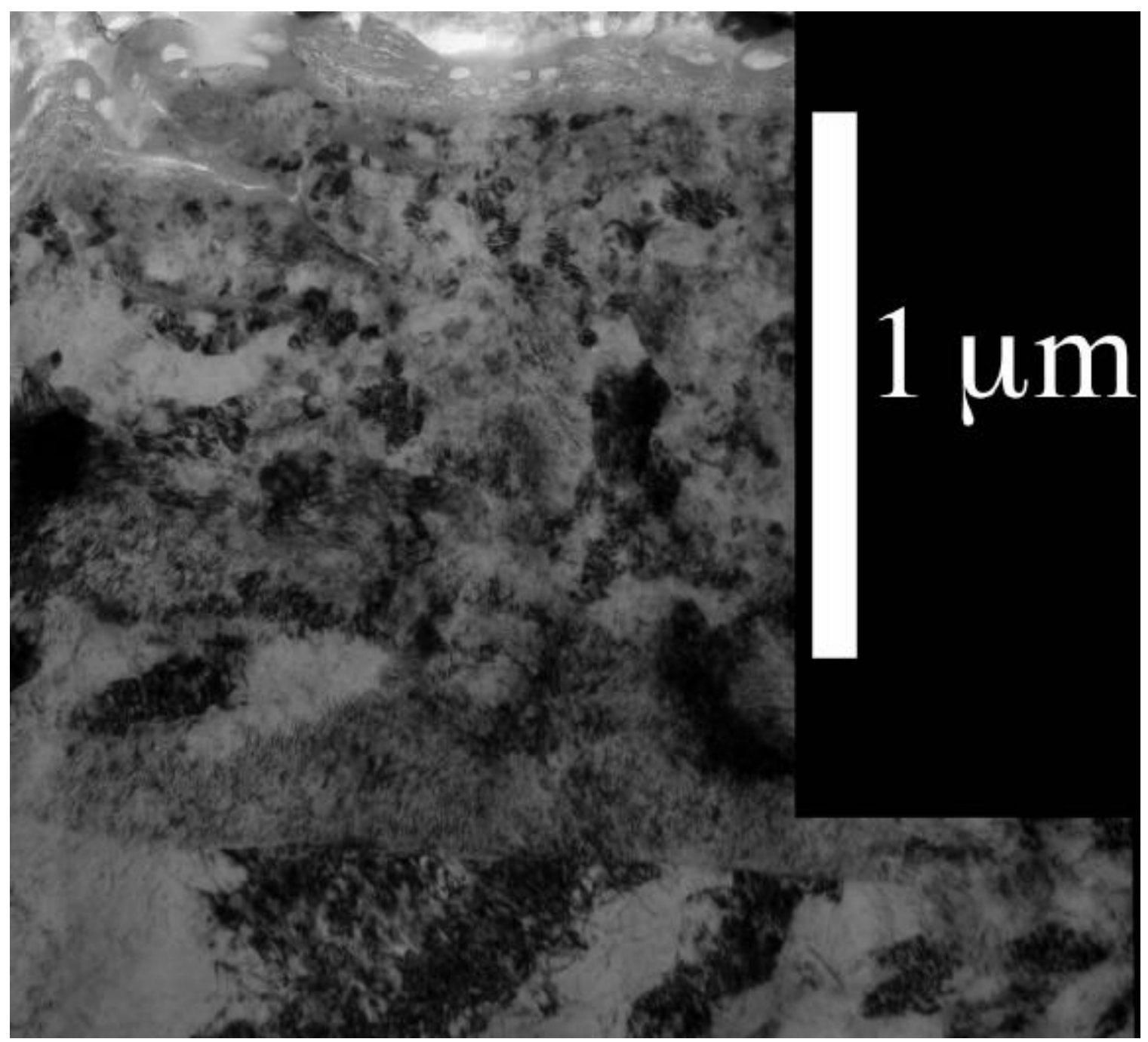

Fig. 7. Cross-sectional transmission electron microscopy image of sample Mo2 that had a $1.4 \mu \mathrm{m}$ melt depth. 

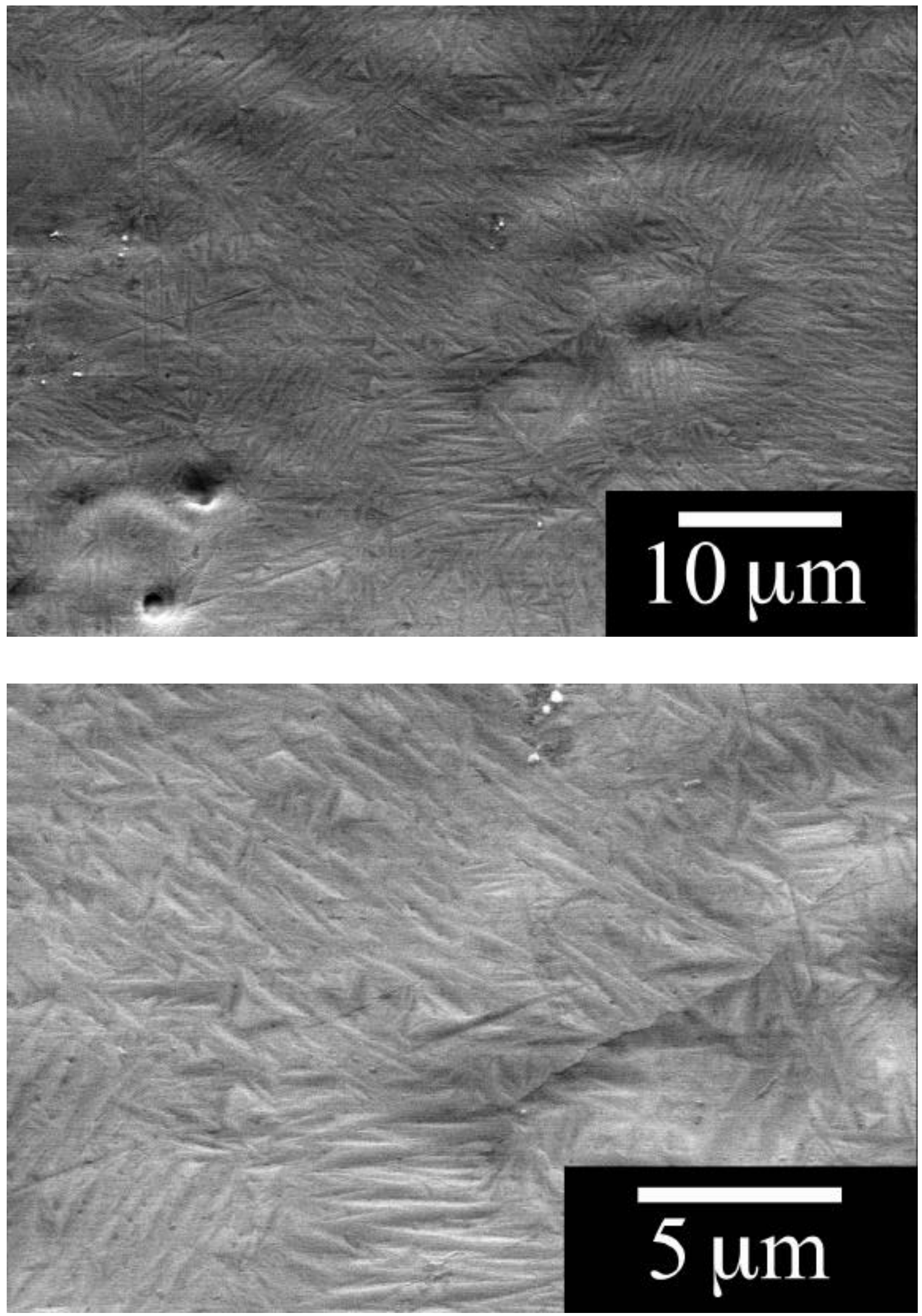
Fig. 8. Scanning electron microscopy images of the surface of sample Hf2, showing the three scales of surface roughness: large variations $(\sim 10 \mu \mathrm{m})$ due to beam inhomogeneities (a), medium-sized craters $(\sim 5$ $\mu \mathrm{m})$ resulting from surface impurities (a), and small features $(\sim 1 \mu \mathrm{m})$ due to the solid-state phase transition (b). 